\title{
CORRESPONDENCE
}

\section{Protect Brazil's land to avert disasters}

The huge mudslides and flooding in Brazil that killed more than 890 people in Rio de Janeiro state have been blamed on heavy rains and soil features. We believe that the main culprits are the country's increasingly chaotic land-use policies.

The 1965 Brazilian Forest Act governs rural land use and guides it in urban areas so that all steep hills, hilltops and forests near water are permanently protected. These areas provide crucial ecosystem services, such as terrain stabilization, flood regulation and water supply.

But after decades of unplanned urban and agricultural expansion in contravention of the Act, natural calamities in Brazil are on the rise. In addition to the recent disaster, landslides and floods in other Brazilian states have killed hundreds of people during the past three years.

The Brazilian congress is now considering a draft bill that excludes hilltops from legal protection, reduces the width of protected areas adjoining small streams, and allows state governments to reduce such areas by up to $50 \%$ more than is permitted under federal rules. The draft bill also gives the municipalities more freedom to slacken land-use standards in urban areas.

Supporters of the new bill have failed to note the link between disregard of protected areas and the rise in natural catastrophes. Instead of enforcing the existing law, they propose to legitimize violations that are likely to contribute to more tragedies. Now, influential agribusiness lobbyists are trying to force a quick vote on this matter to reduce costly compliance pressures on recalcitrant landowners.

As so often happens with environmental issues, the welfare of many is threatened by the interests of a few.

Carlos A. Zucco, Luiz Gustavo

R. Oliveira-Santos, Fernando

A. S. Fernandez Federal

University of Rio de Janeiro,

Brazil.

cazucco@hotmail.com

\section{Balkan science: give support to Bulgaria}

Policies restricting the future funding of Bulgarian science (Nature 469, 131-132 and 142-143; 2011) could have implications for the European Union's research landscape.

Take the contentious issue of genetically modified (GM) organisms. Attempts by the Bulgarian government to amend its laws on GM organisms to comply with EU regulations met with strong opposition in the media. However, the government was unable to garner support and advice from the scientific community, which had previously been alienated by government actions.

As a result, in March 2010, the Bulgarian parliament succumbed to media pressure and imposed severely restrictive amendments on its laws on GM organisms, banning all biotechnology research. It is now forbidden to grow GM plants for trials or commercial cultivation near nature reserves, apiaries or fields of organic produce, or to introduce genetic modifications into tobacco, vines, roses, wheat or any fruit or vegetable crops.

These bans are enforced by fines of between $€ 250,000$ (US\$340,000) and $€ 500,000$ for a first offence, and doubled thereafter. But they are not scientifically justifiable: there is no evidence that transgenic technology is inherently riskier than any other, a matter investigated by the EU over 20 years at a cost of more than $€ 300$ million. The restrictions are apparently acceptable in Bulgaria, however, because science has been publicly discredited (seemingly for shortsighted political purposes).

I therefore appeal to the entire scientific community, not just Bulgaria's, to defend and promote the scientific arguments needed to guide important policy decisions and underpin research proposals.

Bojin Bojinov Agricultural University of Plovdiv, Bulgaria. bojin.bojinov@gmail.com

\section{Balkan science: how to halt the brain drain}

Reforms to Romania's science education and research will provide a fresh start, but will not be easy to implement (Nature $469,142-143 ; 2011)$. Crucial to progress will be more effective selection of high-ranking academics who can improve the quality of research output and serve as mentors for students and junior scientists.

Mentoring programmes in Romanian universities need to become common practice and be properly funded. Since Romania joined the European Union in 2007, grant competition has revitalized its research infrastructure. But intellectually energetic and highly innovative teams are needed to justify expenditure on hi-tech pieces of laboratory equipment.

Steps should be taken now to ensure that the most talented academics are hired. Their work environment must be financially secure to help alleviate the brain drain that still plagues the country's education and research system.

Tudor Luchian Alexandru Ioan Cuza University, Iasi, Romania. luchian@uaic.ro

\section{Forest loss began before bioethanol}

The problem of bioethanol's 'dirty footprint' in Alagoas state in Brazil (Nature 469, 299; 2011) is real and deserves attention. But the historical background bears clarification.

The loss of Atlantic rainforest in Alagoas to sugar cane began well before the 35-year-old national sugar-cane ethanol programme was introduced. Sugar-cane plantations and mills were established in the state in the early seventeenth century, starting on the coastal plains and then moving inland (A. L. S. Santos et al. CampoTerritório 2, 19-37; 2007). The state's forests have been logged for shipbuilding and other uses since the eighteenth century (W. Dean With Broadax and Firebrand Univ. California Press; 1995).

The authors' implication that Alagoas's forests are no longer a biodiversity hotspot is misleading. The entire Brazilian Atlantic Forest is listed as a hotspot precisely because of the huge areas that have been lost. Combined with the forest's richness of endemic plants, this fulfils the two criteria for a biodiversity hotspot (N. Myers et al. Nature 403, 853-858; 2000).

Thomas Michael Lewinsohn State University of Campinas, Brazil. thomasl@unicamp.br

\section{CONTRIBUTIONS}

Correspondence may be sent to correspondence@ nature.com after consulting the author guidelines at http://go.nature.com/ cmchno. Readers are also welcome to comment online on anything published in Nature: www.nature.com/nature. 